Seminar Nasional Teknologi Informasi dan Kedirgantaraan (SENATIK)

Vol. II, 26 November 2016, ISSN: 2528-1666

\title{
Analisis Trafik Telekomunikasi Menggunakan Model Sistem Sharing
}

\author{
Yenni Astuti ${ }^{1}$, Daniel Teguh Rudianto ${ }^{2}$, Agga Prasetya ${ }^{3}$ \\ 1,2,3 Teknik Elektro STTA \\ Jalan Janti, Blok-R, Lanud Adisutjipto, Yogyakarta \\ lyenni.stta@gmail.com
}

\begin{abstract}
The fast progress in telecommunication, especially in data communication, makes anyone get the information they need easily. It also makes more traffic in the channel. The intensity of the traffic is one of the parameters that considered by the telecommunication. In this paper, the intensity of the traffic in an institution is calculated using Sharing System Teletraffic Model. As the result, the traffic load for this experiment is 0.068. It means, the traffic streaming is not categorized as overload.
\end{abstract}

Keywords: telecommunication traffic, sharing system, internet

\section{Pendahuluan}

Teletraffic atau trafik telekomunikasi merupakan salah satu teori di bidang telekomunikasi yang dipelopori oleh ahli matematika dari Jerman bernama A.K. Erlang pada awal abad ke-20. Trafik telekomunikasi dapat dibedakan berdasarkan jaringan yang digunakan, yakni jaringan teleponi, dan jaringan data. Pada jaringan teleponi, trafik dapat berupa jumlah panggilan yang sedang terjadi, baik panggilan yang berhasil maupun panggilan yang gagal. Pada jaringan data, trafik bisa dalam bentuk bit, paket, maupun aliran. Tujuan dari adanya teletrafik adalah untuk mendapatkan informasi mengenai hubungan antara tiga faktor, yaitu kualitas layanan (Quality of Services/ QoS), beban trafik, dan kapasitas sistem. Informasi mengenai hubungan tiga faktor tersebut, kemudian, dapat digunakan untuk mengambil kebijakan yang berkaitan dengan jaringan.

Internet pada saat ini menjadi satu hal yang penting. Beberapa tulisan ilmiah memaparkan penggunaan internet dalam berbagai bidang, misalnya penggunaan internet dalam perbankan [1], pemanfaatan media online yakni facebookuntuk pembelajaran [2], pemanfaatan internet untuk administrasi pemerintahan [3], kekuatan komunitas dalam dunia maya [4], penggunaan internet untuk membuat aplikasi bidang pariwisata [5]. Peningkatan penggunaan Internet ini tentu saja menyebabkan peningkatan aliran data pada jaringan Internet.

Perguruan Tinggi Swasta (PTS) yang sedang berkembang mengalami bertambahnya jumlah mahasiswa, layanan berbasis web, dan kebutuhan akses ke dunia maya. Hal tersebut juga akan meningkatkan kebutuhan lebar pita yang dapat digunakan oleh sivitas akademika. Pada prinsipnya, penambahan besar lebar pita internet akan meningkatkan kualitas layanan di PTS tersebut. Meskipun demikian, pernyataan tersebut perlu dibuktikan dalam bentuk tulisan ilmiah. Untuk alasan tersebut, penelitian ini dilakukan. Penelitian mengenai teletrafik dalam suatu Perguruan Tinggi pernah dilakukan. Penelitian tersebut mengamati aliran Internet di suatu institusi kemudian melakukan analisis yang berkaitan dengan kapasitas sistem, beban trafik, dan kualitas layanan [6]. Meskipun demikian, artikel tersebut belum mengkuantisasikan kualitas layanan secara baik sesuai dengan model sistem berbagi. Pada penelitian ini, suatu data aliran internet dianalisis. Analisis akan menghasilkan kuantisasi laju kedatangan dan laju layanan internet dari aliran internet di tempat tersebut.

Peneliti dari Jerman pernah melakukan simulasi data paket P2P (Peer-to-Peer) yang dibangkitkan oleh klien BitTorrent dalam area WiMAX yang ada di Korea. Penelitian tersebut berkontribusi pada pengembangan framework yang berkaitan dengan 
pemodelan teletrafik dan analisis sistem P2P berdasar arsitektur mesh-pull [7].Penelitian juga pernah dilakukan pada antrian pemroses sharing untuk model M/G/1. Penelitian tersebut mempelajari lebih dalam model M/G/1 untuk trafik yang sangat besar (heavy traffic), khususnya dalam perhitungan waktu tunggu dalam sistem [8].

\section{Metode Penelitian}

Metode Penelitian meliputi penjelasan mengenai metode analisis data, analisis dalam sistem sharing, dan penjelasan mengenai gambaran besar sistem sharing.

\subsection{Metode Analisis Data}

Trafik dapat diklasifikasikan menjadi dua trafik besar, yakni trafik berdasar pensaklaran sirkuit (circuit-switched), dan trafik berdasar pensaklaran paket (packet-switched). Trafik berdasar pensaklaran paket dapat dibagi menjadi dua aras (level), yakni aras paket, dan aras aliran. Aras aliran dapat dibagi lagi menjadi dua jenis, yakni yang bersifat elastis, dan yang bersifat streaming. Bagan klasifikasi trafik ditunjukkan pada Gambar 1.

Penelitian ini melakukan pengambilan data dan analisis trafik pada aras aliran elastik, yakni TCP (Transmission Control Protocol). Pada aras aliran data, dalam skala waktu yang panjang, trafik data dapat dianggap sebagai aliran yang terus menerus. Suatu aliran tunggal dideskripsikan sebagai aliran bit yang kontinu dengan laju (rate) yang bervariasi. Dalam hal ini, aliran tidak dianggap sebagai paket - paket yang bersifat diskrit. Aras aliran dapat diklasifikasikan menjadi dua macam, yang pertama adalah aliran elastik. Pada aliran elastik, laju transmisi disesuaikan dengan kondisi trafik dalam jaringan menggunakan mekanisme kontrol kongesti.

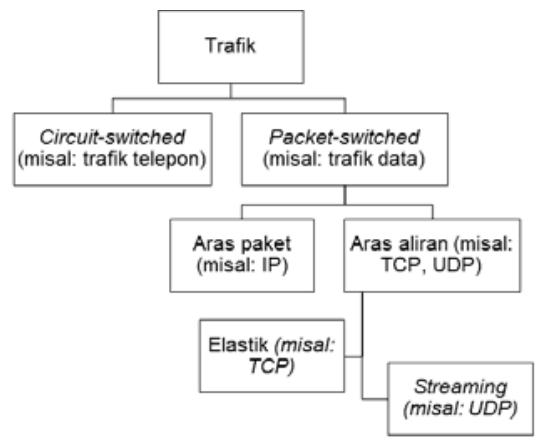

Gambar 1. Klasifikasi trafik
Contoh aliran elastik adalah pengiriman dokumen digital (Hyper Text Transfer Protocoll HTTP, File Transfer Protocol/ FTP) menggunakan TCP. Yang kedua adalah aliran streaming. Pada aliran streaming, laju transmisi bersifat independen terhadap kondisi trafik dalam jaringan. Contoh aliran streaming adalah real time voice, dan transmisi video menggunakan UDP (User Datagram Protocol). Penelitian ini mengambil data aliran internet berupa aliran elastik. Oleh karenanya, aliran streaming tidak dibahas pada metodologi penelitian ini.

Trafik elastik terdiri atas aliran TCP yang bersifat adaptif. Karakterisasi alirannya berupa size (dalam unit data). Laju pengiriman dan durasi dari aliran elastik tidak tetap atau disesuaikan dengan kondisi jaringan secara dinamis. Pemodelan atas trafik yang ditawarkan berupa proses kedatangan aliran (pada saat kapan aliran yang baru datang), dan distribusi size aliran (seberapa besar). Model yang sesuai dengan trafik elastik adalah sistem sharing. Dalam hal ini, tidak ada aliran yang ditolak mengingat kurangnya kendali admisi. Selain itu, laju layanan $(\mu)$ disesuaikan dengan kapasitas sambungan dan rerata size aliran. Pada model ini, adaptasi atas laju transmisi berlangsung secara cepat dan sambungan digunakan bersama-sama oleh pengguna. Pemodelan atas trafik yang dibawa berupa proses trafik yang menyebutkan jumlah aliran yang terdapat dalam sistem.

Pada penelitian ini, aliran data TCP diambil menggunakan aplikasi yang dibuat oleh peneliti, dan dinamai dengan TORCH. Aplikasi ini mengambil data dari mikrotik menggunakan bantuan pemrograman PHP kemudian data tersebut disimpan ke basis data MySQL untuk diolah lebih lanjut.

\subsection{Analisis Sistem Sharing}

Notasi Kendall pada sistem sharing, ada tiga macam. Pertama notasi dalam bentuk $M / M / 1$ $P S$ untuk skenario jumlah pelanggan yang tidak terhingga, jumlah server yang digunakan hanya 1, dan tempat pelanggan dalam sistem tidak terhingga. Bentuk notasi kedua yakni $M / M / n-P S$ untuk skenario jumlah pelanggan tidak terhingga, server sebanyak $n$, dan tempat pelanggan dalam sistem tidak terhingga. Bentuk notasi ketiga yakni $M / M / 1 / k / k-P S$ untuk skenario pelanggan sejumlah $k$, dengan satu buah server, dan $k$ buah tempat tunggu 
pelanggan di dalam sistem. Pada penelitian ini, jumlah server yang diamati hanya satu, sedangkan pelanggan yang dapat masuk ke dalam sistem tidak terhingga. Dengan demikian, notasi yang digunakan pada penelitian ini adalah $M / M / 1-P S$. Notasi tersebut dijadikan metode untuk melakukan analisis atas model. Untuk skenario yang menggunakan notasi $M / M / 1-P S$, beban trafik dapat ditentukan dengan menggunakan Persamaan1.

$$
\begin{aligned}
& \rho=\frac{\lambda}{\mu} \\
& \text { dengan } \\
& \rho=\text { beban trafik } \\
& \lambda=\text { laju kedatangan } \\
& \mu=\text { laju layanan }
\end{aligned}
$$

\subsection{Sistem Sharing}

Sistem sharing dapat dimodelkan dalam bentuk diagram blok seperti pada Gambar 2, dan Gambar 3. Pada Gambar 2, model sistem sharing yang digunakan adalah sharing murni (puresharing). Pada Gambar 3, model sistem sharing yang digunakan adalah sharing hilang (lossysharing). Pada model sharing murni, semua trafik datang akan dilayani oleh sejumlah server. Dalam hal ini, tidak ada trafik yang ditolak, namun tundaan (delay) aliran menjadi semakin besar seiring dengan banyaknya trafik masuk. Pada model sharing hilang, trafik datang dilayani oleh sejumlah server hingga server penuh dan antrian dalam sistem penuh. Dalam hal ini, jika trafik datang melebihi kapasitas server $(n)$ dan ruang antrian $(m)$, maka trafik akan ditolak sistem. Pada penelitian ini, aliran internet dianalisis menggunakan model sistem sharing murni yang diagram bloknya dapat dilihat pada Gambar 2 .

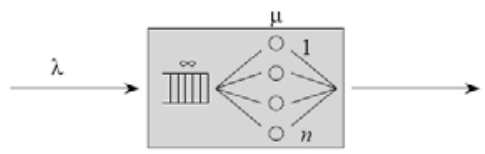

Gambar 2. Model sistem sharing murni

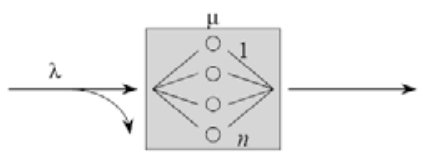

Gambar 3.Model sistem sharing hilang

\section{Hasil dan Pembahasan}

\subsection{Pemodelan}

Pada penelitian ini, digunakan mikrotik yang dapat digunakan untuk melihat aliran data yang masuk maupun keluar dari server. Dari hasil pengamatan, dapat dibuat suatu model (lihat Gambar 4) yang bisa digunakan untuk memberi gambaran mengenai aliran data, yang pada tahap berikutnya dikumpulkan.

Dari Gambar 4 dapat dilihat bahwa penelitian ini hanya mengamati aliran data dari dan ke server. Dengan demikian, sisi sebelah kiri, yakni sisi mikrotik ke pengguna (client), dan sebaliknya, diabaikan. Pada pengambilan data aliran internet mikrotik, yang dimaksud dengan $T x$ adalah aliran yang ditransmisikan dari mikrotik ke server. Aliran ini dapat berisi permintaan data dari server. Sedangkan $R x$ adalah aliran yang ditransmisikan dari server ke mikrotik atau yang diterima mikrotik sebagai jawaban atas permintaan $T x$. Beberapa informasi tersebut sangat dibutuhkan dalam melakukan analisis terhadap data yang terkumpul dari mikrotik.

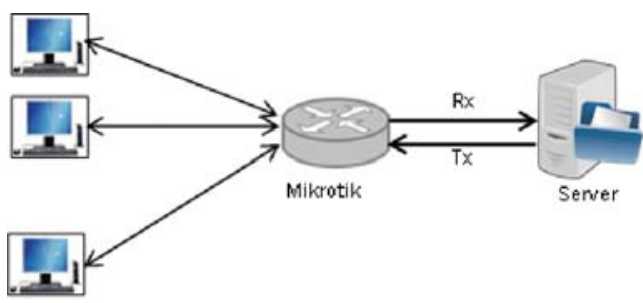

Gambar 4.Pemodelan Server - Mikrotik

\subsection{Pengumpulan Data}

Pengumpulan data dilakukan secara otomatis dari pukul 10.00 sampai dengan pukul 10.59 WIB. Data dikumpulkan menggunakan aplikasi bernama "torch" yang dibangun dan dimodifikasi oleh tim peneliti. Dalam hal ini, aplikasi bernama "torch" akan menarik rekaman aliran data dari dan ke server (melalui mikrotik) untuk kemudian disimpan dalam basis data MySQL. Data yang disimpan dalam basis data tersebut berupa informasi tanggal dan waktu, jenis protokol yang sedang mengalir, jenis protokol transportasi yang digunakan dari protokol yang sedang mengalir, besarnya aliran dalam satuan bit per detik, dan besarnya aliran dalam satuan paket per detik.

Dari basis data MySQL tersebut, data kemudian, diubah kedalam bentuk format CSV (Comma Separated Value). Data dalam bentuk CSV 
ini kemudian diolah dan dijadikan bahan untuk analisis.

Data dari basis data disortir sehingga hanya ada data dengan tipe protokol transportasi "TCP". Pada penelitian ini, pembahasan dilakukan untuk tipe aliran TCP dengan bentuk aliran bit tiap detik (bit per second atau bps).

\subsection{Hasil Pengumpulan Data}

Pada bagian ini dibahas mengenai hasil pengumpulan data beserta pembahasan.

Hari pertama pengamatan dilakukan pada Tanggal 14 Maret 2016. Grafik trafik pada tanggal tersebut, dapat dilihat pada Gambar 5.

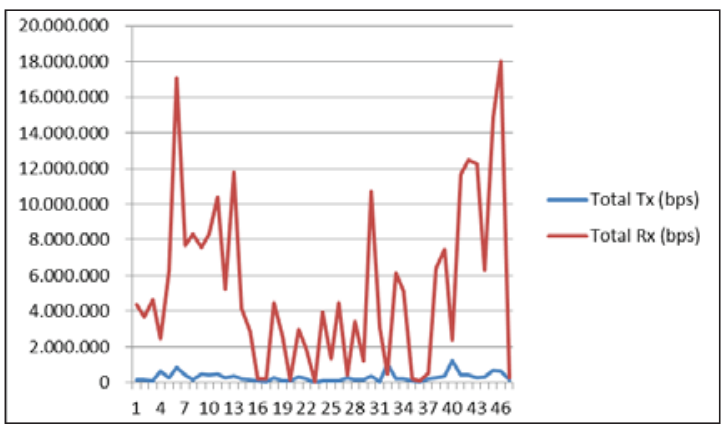

Gambar 5 Grafik pengamatan hari ke-1

Dari data hari pertama ini, total aliran datang ke server $(T x)$ selama 60 menit adalah 13.846 .742 bit per detik. Total aliran keluar dari server $(R x)$ selama 60 menit adalah 250.432 .076 bit per detik. Rerata aliran $T x$ diperoleh dengan cara membagi nilai $T x$ terhadap durasi waktu, yakni 13.846 .742 bit per detik dibagi dengan60 menit yang menghasilkan angka sebesar 230.779 bit per detik tiap satu menit. Sedangkan rerata aliran $R x$ diperoleh dengan membagi nilai $R x$ terhadap durasi waktu pengamatan, yakni 250.432.076 bit per detik dibagi dengan 60 menit, dan diperoleh angka sebesar 4.173 .868 bit per detik. Nilai tersebut merupakan pengamatan selama 60 detik.

Dari Gambar 5, aliran $T x$ tertinggi terjadi pada pukul 10:39 WIB dengan angka sebesar 1.217.106 bit per detik. Sedangkan untuk aliran $R x$ tertinggi terjadi pada pukul 10:45 WIB dengan nilai sebesar 18.052.864 bit per detik.

Hasil pengamatan selama 20 hari disajikan dalam bentuk tabel. Tabel 1 merupakan tabel total $T x$ dan $R x$ pada 20 hari pertama, yang grafiknya ditampilkan pada Gambar 6.
Tabel 1 Total Tx dan Rx per hari

\begin{tabular}{|c|c|c|}
\hline Hari ke-\# & Tx (bps) & Rx (bps) \\
\hline 1 & 13.846 .742 & 250.432 .076 \\
\hline 2 & 14.838 .391 & 231.446 .214 \\
\hline 3 & 22.532 .387 & 273.960 .158 \\
\hline 4 & 27.838 .748 & 340.774 .480 \\
\hline 5 & 16.973 .296 & 307.141 .744 \\
\hline 6 & 12.174 .400 & 253.712 .856 \\
\hline 7 & 14.459 .544 & 418.007 .752 \\
\hline 8 & 82.180 .776 & 262.691 .440 \\
\hline 9 & 437.412 .177 & 6.697 .915 .895 \\
\hline 10 & 558.780 .915 & 8.734 .331 .087 \\
\hline 11 & 8.885 .560 & 168.324 .160 \\
\hline 12 & 15.259 .536 & 232.162 .176 \\
\hline 13 & 31.015 .087 & 207.448 .110 \\
\hline 14 & 13.415 .377 & 137.931 .626 \\
\hline 15 & 14.123 .744 & 306.166 .456 \\
\hline 16 & 13.857 .024 & 235.844 .128 \\
\hline 17 & 16.548 .420 & 220.688 .792 \\
\hline 18 & 18.850 .940 & 265.434 .256 \\
\hline 19 & 10.602 .032 & 200.398 .312 \\
\hline 20 & 11.371 .240 & 135.275 .816 \\
\hline TOTAL & 1.354 .966 .336 & 19.880 .087 .534 \\
\hline & & \\
\hline
\end{tabular}

\subsection{Waktu Puncak}

Dari data yang telah diperoleh selama dua puluh hari, dapat ditemukan waktu paling banyak terjadi aliran data. Waktu puncak diketahui dengan menjumlahkan data pada menit yang sama kemudian hasil penjumlahan tersebut dibagi dengan banyaknya hari (yakni 20 hari).

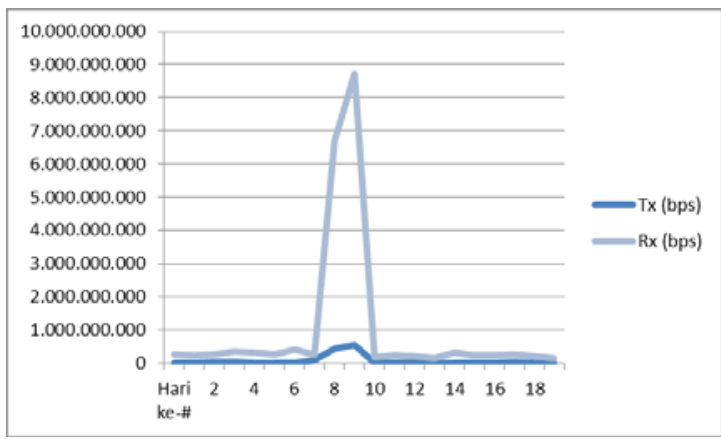

Gambar 6. Grafik total per hari sesuai Tabel 1 
Dari hasil perhitungan dapat diketahui bahwa waktu puncak, yakni waktu ketika aliran TCP paling banyak, adalah pada pukul 10:13 untuk data $T x$, 10:44 untuk data $R x$. Jika nilai puncak $T x$ dan $R x$ dijumlahkan, maka dapat diketahui bahwa waktu puncak untuk penjumlahan Tx dan Rx terjadi pada pukul 10:44.

\subsection{Laju Kedatangan}

Dari hasil perhitungan, diperoleh rerata laju kedatangan aliran ke server $(T x)$ selama 20 hari, yakni sebesar 1.129.139 bit per detik.

\subsection{Laju Layanan}

Dari hasil perhitungan, diperoleh rerata laju layanan aliran dari server $(R x)$ selama 20 hari, yakni sebesar 16.566 .740 bit per detik.

\subsection{Beban Trafik ( $\rho)$}

Perbandingan laju kedatangan dengan waktu layanan dapat dihitung dengan menggunakan rumus 1, Pada penelitian ini, diketahui nilai $\lambda, \mu$, dan $n$, sebagai berikut (persamaan 2).

$$
\begin{aligned}
& \lambda=1.129 .139 \text { bit per detik } \\
& \mu=16.566 .740 \text { bit per detik } \\
& n=1 \text { buah server }
\end{aligned}
$$

Nilai - nilai pada persamaan 2 disubstitusikan ke dalam persamaan 1 , menjadi persamaan 3 sampai dengan persamaan 5 .

$$
\begin{aligned}
& \rho=\frac{1.129 .139}{1 \times 16.566 .740} \\
& \rho=\frac{1.129 .139}{1 \times 16.566 .740} \\
& \rho=0,068
\end{aligned}
$$

Dari hasil perhitungan, yakni dari Persamaan 5 , diperoleh nilai beban trafik sebesar 0,068. Secara teori, nilai beban trafik dikatakan baik jika nilainya dibawah satu. Nilai pada persamaan 5 secara kualitatif sangat jauh dari nilai satu sehingga beban trafik hasil analisis untuk institusi A ini adalah baik.

\section{Kesimpulan}

Dari hasil penelitian yang telah dilaksanakan, sejumlah kesimpulan yang dapat diambil, sebagai berikut.

1. Rerata laju kedatangan aliran ke server $(T x)$ selama 20 hari, yakni sebesar 1.129.139 bit per detik. Nilai ini lebih kecil dari laju layanan.

2. Rerata laju layanan aliran dari server $(R x)$ selama 20 hari, yakni sebesar 16.566 .740 bit per detik. Nilai ini lebih besar daripada laju kedatangan. Artinya dalam sistem ini tidak terjadi overflow.

3. Beban trafik dari hasil penelitian ini sebesar 0,068 . Nilai ini artinya beban trafik masih dikatakan baik atau tidak overload.

\section{Saran}

Dari hasil penelitian ini, beberapa saran yang diperoleh, sebagai berikut.

1. Penelitian ini memerlukan waktu pengamatan yang lebih banyak untuk memperoleh trend pengamatan yang lebih akurat.

2. Penelitian ini dapat dikembangkan untuk melihat trafik jaringan dengan parameter lainnya, seperti protokol transportasi UDP.

3. Penelitian ini dapat ditambahkan perhitungan throughput untuk memperoleh nilai kuantitatif QoS.

\section{Ucapan Terima kasih}

Penulis mengucapkan terima kasih kepada Kementerian Riset Teknologi Dan Pendidikan Tinggi Republik Indonesia yang telah memberi dukungan finansial terhadap penelitian ini melalui skim Penelitian Dosen Pemula 2016. 


\section{DAFTAR PUSTAKA}

[1] Hermana, B. (2011). Pengukuran kualitas layanan internet banking. Jurnal Ilmiah Ekonomi Bisnis, 15(1).

[2] Patria, L., \& Yulianto, K. (2010). Pemanfaatan Facebook untuk Menunjang Kegiatan Belajar Mengajar Online Secara Mandiri. Makalah tidak diterbitkan.

[3] Djunaedi, A. (2002). Beberapa Pemikiran Penerapan e-Goverment Dalam Pemerintahan Daerah di Indonesia. In Seminar Nasional E-Government \& Workshop Linux. Fakultas MIPA UGM. Yogyakarta (Vol. 30).

[4] Purbo, O. W. (2002). Kekuatan Komunitas Indonesia di Dunia Maya. Panatau,2, 22.

[5] Mulyani, E. S., \& Kusuma, W. (2012). Aplikasi Location Based Service (LBS) Taman
Mini Indonesia Indah (TMII) Berbasis Android. Jurnal Program S1 Sistem Informasi Universitas Gunadarma.

[6] Astuti, Yenni. (2016). Teletrafik Sistem Berbagi Pada Aliran Internet. Proceedings Seminar Nasional RETII. Yogyakarta.

[7] Eittenberger, P. M., Krieger, U. R., \& Markovich, N. M. (2012, December). Teletraffic modeling of peer-to-peer traffic. In Proceedings of the 2012 Winter Simulation Conference (WSC) (pp. 1-12). IEEE.

[8] Zwart, A. P., \& Boxma, O. J. (2000). Sojourn time asymptotics in the $\mathrm{M} / \mathrm{G} / 1$ processor sharing queue. Queueing systems, 35(1-4), 141-166. 